\title{
Aplicação do Método VERAH no Diagnóstico Ambiental de uma Microbacia no Estado de Mato Grosso-Brasil
}

\section{Application of the VERAH Method in the Environmental Diagnosis of a Microbasin in the State of Mato Grosso, Brazil}

\author{
${ }^{1}$ Aline Nayara Rodrigues São Pedro, ${ }^{2}$ Ana Paula Rodrigues São Pedro, ${ }^{3}$ Margarida Marchetto \\ ${ }^{1}$ Mestre em Recursos Hídricos pela Universidade Federal de Mato Grosso - UFMT \\ (aline.sepdro@outlook.com) \\ ${ }^{2}$ Pós-Graduanda do Curso de Sustentabilidade da Faculdade de Economia da Universidade Federal de Mato \\ Grosso UFMT (ana.rsp@ hotmail.com) \\ 3Professora Doutorado Departamento de Engenharia Sanitária e Ambiental da \\ Universidade Federal de Mato Grosso - UFMT \\ (marchetto.ro@gmail.com)
}

\begin{abstract}
RESUMO: O aumento da população da cidade de Cuiabá e o consequente incremento da demanda de água reforçam a ideia de que medidas de recuperação e conservação das microbacias são necessárias. Todos os setores de atividades humanas precisam de água para desempenhar suas funções, por isso ela é apontada como um recurso natural de altíssimo valor econômico, estratégico e social, no entanto o descaso e a falta de planejamento aliado ao crescimento desordenado das cidades tem levado a destruição dos córregos urbanos. A urbanização é um processo que acarreta diversas complicações para as cidades, como alagamentos, enchentes e inundações. Estes problemas são recorrentes em zonas urbanas e causam inúmeros prejuízos tanto para a população quanto para o poder público. Dessa maneira a realização de estudos sobre o gerenciamento ambiental dos espaços urbanos é de elevada relevância. A metodologia utilizada neste trabalho foi diagnóstico ambiental da microbacia do Córrego do Barbado, localizado na zona urbana de Cuiabá pelo método VERAH em que foram abordados os temas vegetação, erosão, resíduos sólidos, água e habitação. Os resultados mostraram que o córrego do Barbado sofre com diversos problemas como: escassez de área verde na microbacia; o alto índice de urbanização, a ineficiência ou inexistência dos sistemas coletores de águas pluviais, etc., tendo influência direta no comportamento hidrológico da bacia contribuindo para as ocorrências de alagamentos de inundações no trecho do córrego da Avenida Fernando Correa da Costa. O estudo também apontou que ocupação urbana impacta a qualidade ambiental da bacia.
\end{abstract}

Palavra-chave: Córrego do Barbado, Avaliação ambiental, Microbacias urbanas.

ABSTRACT: The increase in the population of the city of Cuiabá and the consequent increase in the demand for water reinforce the idea that measures for the recovery and conservation of watersheds are necessary. All sectors of human activities need water to perform their functions, so it is pointed out as a natural resource of very high economic, strategic and social value; however the neglect and lack of planning combined with the disorderly growth of cities has led to destruction of urban streams. Urbanization is a process that entails several complications for cities, such as floods, floods and floods. These problems are recurrent in urban areas and cause numerous damages for both the population and the public power. In this way the realization of studies on the environmental management of urban spaces is of great relevance. The methodology used in this study was the environmental assessment of the Barbado Creek watershed, located in the urban area of Cuiabá, by the VERAH method, which addressed vegetation, erosion, solid waste, water and housing. The results showed that the Barbado stream suffers from several problems such as: scarcity of green area in the microbasin; the high rate of urbanization, the inefficiency or nonexistence of rainwater harvesting systems, etc., having a direct influence on the hydrological behavior of the basin, contributing to the occurrence of flooding in the stretch of the Fernando Correa da Costa Avenue stream. The study also pointed out that urban occupation impacts the environmental quality of the basin

Keywords: Barbado stream, Environmental assessment, Urban microbasins.

\section{INTRODUÇÃO}

As áreas que se aproximam dos sistemas hídricos são chamadas de matas ciliares igualmente conhecidas como Áreas de Preservação Permanente (APPs), as mesmas desempenham funções muito importantes na manutenção da qualidade das águas, na estabilidade dos solos, na regularização dos regimes hídricos, na questão das 
cheias/inundações, no processo de controle do assoreamento dos rios, contribuindo, finalmente, para o sustento da fauna aquática e terrestre (SOARES et al, 2012).

As matas ciliares são de vital importância na proteção de mananciais, controlando a chegada de nutrientes, sedimentos e a erosão das ribanceiras, atuam na interceptação e absorção da radiação solar, contribuindo para a estabilidade térmica da água, determinando assim as características físicas, químicas e biológicas dos cursos d'água). A busca por formas de reduzir a agressão que é exercida sobre a natureza passa a ser cada vez mais importante, principalmente em um mundo onde o processo de urbanização é desordenado e os recursos naturais limitados (DELITTI, 1989).

A urbanização acarreta diversas complicações para as cidades como alagamentos, enchentes e inundações entre outros problemas e são recorrentes em zonas urbanas causando inúmeros prejuízos à população e poder público (TUCCI, 2007) e na cidade de Cuiabá está situação não é diferente.

O córrego do Barbado, localizado em uma importante microbacia da área urbana de Cuiabá no estado de Mato Grosso, apresenta nos períodos chuvosos ocorrências de alagamentos e inundação em alguns pontos de suas áreas marginais. Historicamente, esses problemas têm sido observados principalmente os alagamentos na região do entroncamento entre as Avenidas Brasília e Av. Parque do Barbado, no acesso à Universidade Federal de Mato Grosso - UFMT e nas Avenidas Tancredo Neves e Fernando Corrêa da Costa (está última importante via estrutural da cidade) ruas estas paralelas ao Córrego do Barbado. Estes problemas se intensificaram em frequência e altura da lâmina d' água no final de 2013 com a construção do Viaduto Clovis Roberto Queiroz vulgarmente chamado de "Viaduto da UFMT" obra realizada com intuito de melhorar a mobilidade urbana em função da capital, Cuiabá ser uma das cidades sede da copa de 2014.

Em meio a este cenário justifica- se a necessidade de ações de planejamento e gestão da microbacia, a fim de identificar os fatores que agravam os eventos de alagamento e inundação em alguns pontos do córrego, a ser realizado por meio de diagnóstico ambiental e sugestão de medidas que possibilitem a minimização dessas ocorrências.

Nos últimos anos, estudos vêm sendo realizados com intuito propor ações de planejamento e gestão para impactos ambientais recorrentes em microbacias urbanas. Santos (2013) realizou diagnóstico ambiental da microbacia do Córrego Três Barras, localizada no município de Cuiabá-MT com intuito de verificar a influência dos processos de ocupação urbana e a implantação de uma avenida adjacente ao córrego. A metodologia utilizada foi o método VERAH, proposto por Oliveira et al. (2008) analisando aspectos ambientais quanto à vegetação, erosão, resíduo, água e habitação. Os resultados mostraram que embora a forma da bacia seja caracterizada como não suscetível a enchentes, não indicando tendências a inundações, esse aspecto físico foi alterado em decorrência da ocupação urbana de maneira irregular. Isso vem contribuindo com o aumento da vazão pluvial, sobrecarregando o sistema de drenagem provocando, conforme a intensidade das precipitações, inundações em porções mais baixas da bacia, aumento dos processos erosivos das margens do córrego, deterioração da qualidade da água, colocando em risco os recursos hídricos. Rosin et al. (2014) avaliou a microbacia do Córrego do Gambá em Cuiabá-MT, com a finalidade de subsidiar dados para os planos de bacias a serem realizados no município. A metodologia utilizada foi o método VERAH, proposto por Oliveira et al. (2008). Os resultados demonstraram processo de urbanização sem planejamento provocou o desmatamento de grande parte da vegetação natural da microbacia, principalmente nas APP. As características fisiográficas da microbacia apontam baixo risco à inundação, porém a maior parte do relevo é pertencente à classe moderadamente ondulado, o que dificulta a infiltração de água no solo, favorecendo assim o escoamento superficial. A pesquisa concluiu que os resultados alcançados podem auxiliar na tomada de decisão sobre o uso do solo mais adequado, impedir o avanço do processo de 
degradação e mitigar os impactos já existentes.

Neste contexto este artigo apresenta parte da pesquisa que teve como objetivo realizar um diagnóstico ambiental da microbacia do Córrego do Barbado, Cuiabá-MT, utilizando o método VERAH (Vegetação, Erosão, Resíduos sólidos, Água e Habitação) com a finalidade de identificar os fatores que agravam os problemas frequentes na bacia, propor medidas preventivas e corretivas, a fim de subsidiar dados para planejamento e gestão da bacia.

\section{MATÉRIAS E MÉTODOS}

\section{1 Área de estudo}

A área de estudo é a microbacia do Córrego do Barbado inserida na porção centro-leste da cidade de Cuiabá (Figura 1) localizada no estado de Mato Grosso, Brasil tem como principal curso d'água o Córrego do Barbado o qual é uma das sub-bacias afluentes do Rio Cuiabá, sendo este afluente do Rio Paraguai, que drena o Pantanal Mato-Grossense (COLET, 2012).

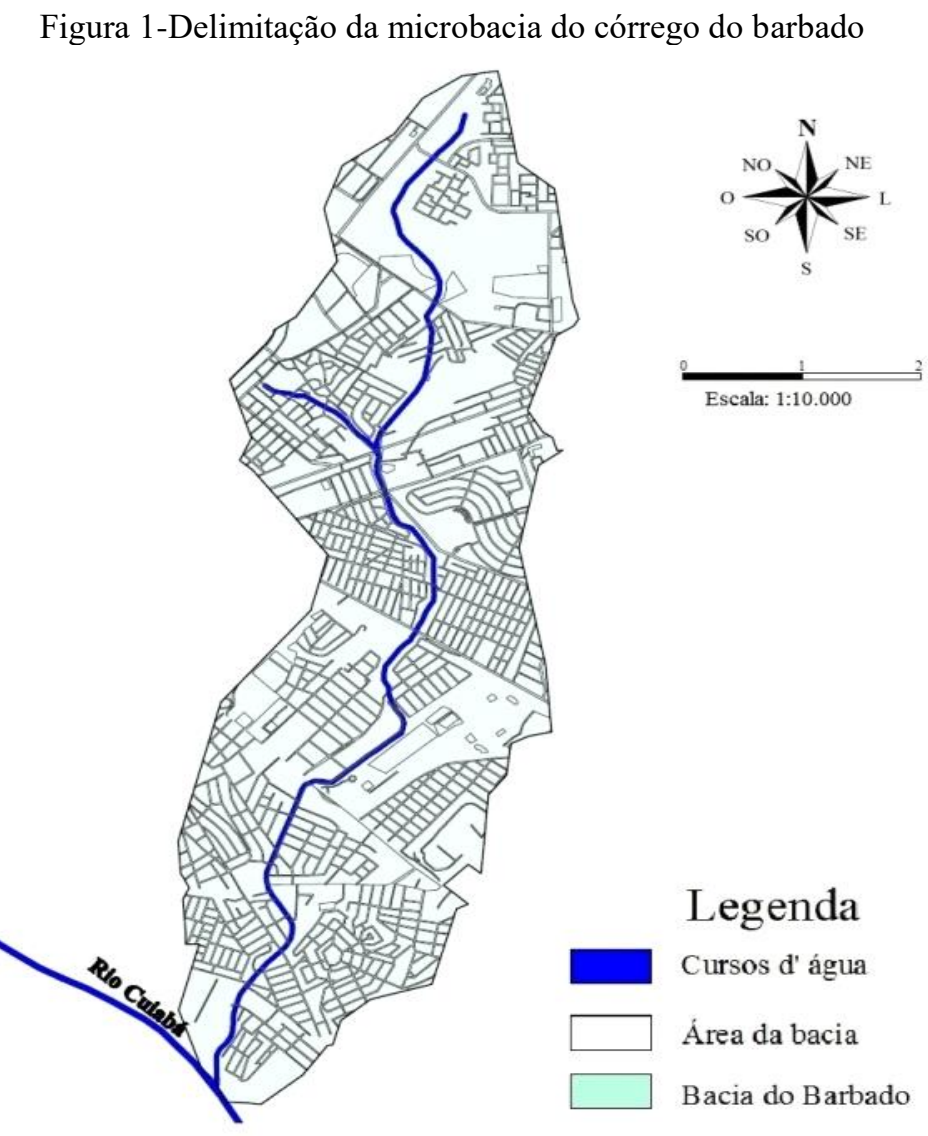

Fonte: Autores (2017)

Segundo Colet (2012) o córrego encontra-se totalmente inserido na área urbana de Cuiabá, com 25 bairros, estando 22 bairros inseridos na área da bacia com aproximadamente 66,166 habitantes de acordo com estimativa realizada pelo Plano municipal de saneamento básico de Cuiabá do ano de 2012.

O córrego do Barbado percorre aproximadamente $8,95 \mathrm{~km}$ de extensão, desde sua nascente $\left(15^{\circ} 33^{\prime} 56,07^{\prime}\right.$ 'S e $\left.56^{\circ} 03^{\prime} 52,71^{\prime \prime} \mathrm{O}\right)$ até sua foz $\left(15^{\circ} 38^{\prime} 00,08^{\prime}\right.$ 'S e $\left.56^{\circ} 04^{\prime} 48,76^{\prime \prime} \mathrm{O}\right)$, a bacia do Córrego do Barbado tem formato elíptico, com largura de 1,4 km e área total de $13,89 \mathrm{~km}^{2}$ (CUIABÁ, 2010). 
São Pedro, Aline; et al; Aplicação do Método VERAH no Diagnóstico Ambiental de uma Microbacia no Estado de Mato Grosso-Brasil. E\&S - Engineering and Science, (2018), 7:1

\subsection{Diagnóstico ambiental da microbacia}

Para a elaboração do diagnóstico ambiental da bacia do Córrego do Barbado foi utilizado o método VERAH, proposto por Oliveira et al. (2008).

O método VERAH surgiu do pensamento de se obter um diagnóstico dos componentes ambientais, que culminaria em ações em prol da educação e gestão ambiental, principalmente em áreas urbanas (SANCHÉZ, 2008).

Segundo Pontuschka et al. (2007), o método provoca a reflexão diante da paisagem contemplada, seus procedimentos envolvem a problematização, observação, descrição, registro, síntese, representação e análise dos fenômenos naturais, sociais e culturais que envolvem o espaço. Salienta ainda que esta prática é interdisciplinar e contextualizada. Diferente de métodos científicos, onde são usados procedimentos intelectuais e técnicos para se atingir o conhecimento, o método VERAH é empírico, ou seja, baseado nas observações vivenciadas do meio ambiente em questão, sendo possível ter apenas uma intuição intelectual e se basear nela para obter resultados desenvolvendo assim a consciência social e ambiental, promovendo o debate sobre o equilíbrio ambiental.

Os componentes do VERAH (Vegetação, Erosão, Resíduos, Água e Habitação) encontram se interligados na dinâmica do meio ambiente e conhecendo cada um, podemos conhecer a conexão entre eles, suas relações, causas e efeitos, com isso os problemas diagnosticados passam a ser analisados, corrigidos e evitados (OLIVEIRA, 2008).

Segundo Souza (2013), as iniciais que compõem o termo VERAH (vegetação, erosão, resíduos, água e habitação) são definidas como:

a) V - Vegetação

Tipo (árvore, arbusto, herbácea, se é espécie agrícola, exótica ou nativa etc.), formação (se é isolada ou em maciços etc.), situação (se está em uma gleba, em um sítio, em um quintal, na rua, na margem de nascentes e/ou córregos, em topo de morro, em encostas etc.).

b) E - Erosão e escorregamento

Dimensões aproximadas (comprimento, profundidade, largura), situação (se está em uma rua, em um terreno, próximo ao topo, em uma encosta, no fundo de vale, junto ao córrego ou às nascentes, se está causando problemas/avarias às ruas, aos edifícios etc.).

c) R - Resíduos sólidos

Volume (quantos caminhões para retirar), tipo (doméstico, industrial, hospitalar, entulho de construção, resto de podas de vegetação etc.), situação (úmido, queimado, se apresenta odor, chorume, vetores de doenças, como ratos, baratas, moscas etc. ou presença de animais como cães e cavalos).

d) A - Água

Vazão, situação (nascente, córrego, lagoa, empoçamento, águas servidas), se apresenta cor, odor etc. ou, se indica a presença de galerias e canalizações de águas e de rede de esgoto. Caso apresente assoreamento: dimensão aproximada, natureza do material, se está causando problemas etc.

e) H - Habitação

Tipologia (residencial, comercial ou industrial), barraco, alvenaria, galpão, térreo, sobrado, se ocupa o lote inteiro ou não, se apresenta avarias, acabamento, risco a escorregamento ou enchentes etc.

Para realização do diagnóstico ambiental da microbacia foram realizados levantamentos de dados primários e secundários.

A base de dados primários consistiu em levantamento de campo, com aplicação de questionários e observações de campo com auxílio de checklist. Já os dados secundários constituíram em levantamento na literatura cerca do tema. 
Para melhor entendimento dos resultados e facilidade na coleta de dados de campo, a microbacia foi dividida em 3 regiões: alto curso, médio curso e baixo curso do rio (Figura 5), conforme estudo de Faria (2013).

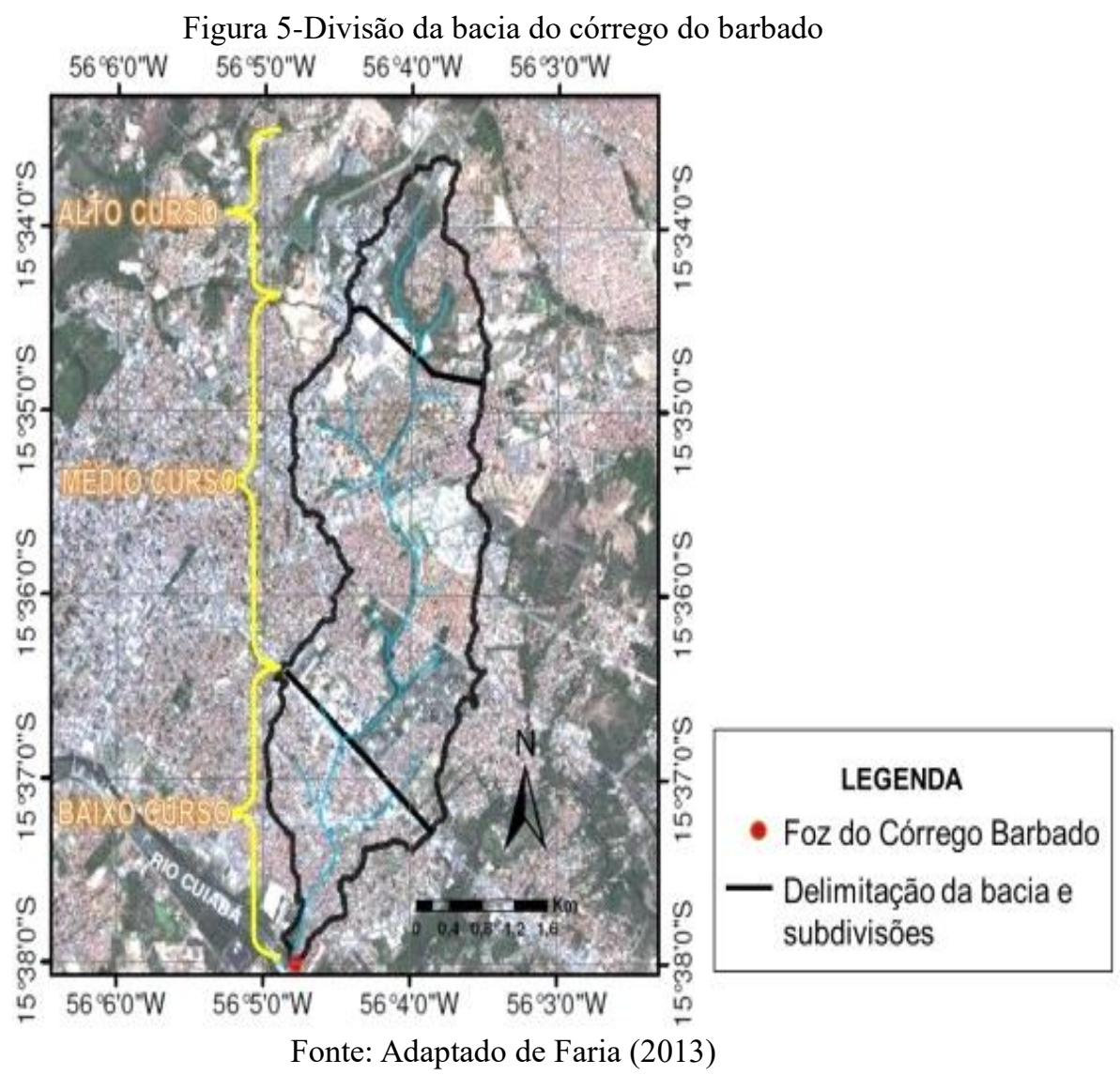

Dos 22 bairros inseridos na microbacia do Córrego do Barbado, 13 encontram-se dentro da faixa de APP de 30 metros, conforme Código Florestal No 12.651 de 2012.

Nestes 13 bairros da faixa de APP foram realizadas observações de campo com auxílio de checklist. A divisão dos bairros conforme Faria (2013), ficou: Alto curso (Morada do Ouro, Bela Vista, Terra Nova, Canjica, Campo Verde e Dom Bosco.), Médio curso (Pedregal, Jardim da Américas, Jardim Leblon.) e baixo curso (Jardim Petrópolis, Campo Velho, Praeiro e Praeirinho).

A seguir serão descritas em detalhes as metodologias empregadas para cada tema do estudo do VERAH (Vegetação, Erosão, Resíduos sólidos, Água e Habitação).

\subsubsection{Vegetação}

Foram realizadas a identificação e a quantificação das áreas verdes existentes por meio de interpretação de imagem de satélite, fornecido pelo programa Landsat-7 do ano de 2014 e georreferênciadas no programa ARCGIS versão 10.3. Após a identificação foi elaborado um mapa com informações sobre áreas verdes, faixas de APP recomendadas e as áreas de APP existentes na bacia.

Para fins de conferência dos dados coletados por imagem de satélite, realizou-se visita de campo em toda a faixa de APP do Córrego do Barbado, com auxílio de um checklist (Quadro 2) contendo 17 itens no total, abordando todos os temas do VERAH. As observações de campo foram realizadas de carro, foi percorrida toda a margem do curso d' água dos 13 bairros pertencentes às faixas de APP do Córrego do Barbado.

Para o tema vegetação foram preenchidos os campos: existência de vegetação 
São Pedro, Aline; et al; Aplicação do Método VERAH no Diagnóstico Ambiental de uma Microbacia no Estado de Mato Grosso-Brasil. E\&S - Engineering and Science, (2018), 7:1.

característica, solo exposto, derrubada e ou desmatamentos das áreas de APP.

Quadro 2- Checklist de levantamento de campo método VERAH

\begin{tabular}{|c|c|c|c|}
\hline \multicolumn{4}{|c|}{ Checklist de auxílio método VERAH } \\
\hline \multicolumn{4}{|l|}{ Trecho/bairro: } \\
\hline \multicolumn{2}{|r|}{ Fator de Degradação } & Sim & Não \\
\hline \multirow{3}{*}{ Vegetação } & Vegetação característica & & \\
\hline & Solo exposto & & \\
\hline & Derrubada de vegetação /Desmatamento/ queimadas & & \\
\hline \multirow{4}{*}{$\begin{array}{c}\text { Erosão e } \\
\text { instabilidade de } \\
\text { Encostas }\end{array}$} & Presença de vegetação nas encostas & & \\
\hline & Obras de engenharia para contenção de encostas & & \\
\hline & Presença de assoreamento ou deslizamento de terra & & \\
\hline & Ocupações irregulares na faixa de APP & & \\
\hline \multirow{6}{*}{ Resíduos Sólidos } & Lançamento de resíduos dentro do córrego & & \\
\hline & Resíduos nas margens do córrego & & \\
\hline & Bolsões de lixo & & \\
\hline & Aves de Rapina-Urubus & & \\
\hline & Animais domésticos & & \\
\hline & Animais peçonhentos & & \\
\hline \multirow{3}{*}{ Água / esgoto } & Lançamento de esgoto in natura no córrego & & \\
\hline & Algas verdes na água & & \\
\hline & Odor na água & & \\
\hline \multirow{3}{*}{ Habitação } & Ocupação irregular de APP & & \\
\hline & Tipo de ocupação (residencial ou comercial) & & \\
\hline & Acesso a saneamento básico dos moradores ribeirinhos & & \\
\hline
\end{tabular}

Fonte: Autores (2017)

\subsubsection{Erosão ou instabilidade de encosta}

No tema erosão também foi utilizado o checklist como ferramenta para levantamento de dados. As observações consistiram em verificar existência de vegetação nas encostas do córrego, presença de assoreamento ou deslizamento de terra, existência de obras de engenharia para contenção de encostas e ocupação irregular da faixa de APP (Quadro 2).

\subsubsection{Resíduos Sólidos}

O diagnóstico de resíduos sólidos abordou o índice de cobertura de coleta, a quantidade coletada e a gravimetria dos resíduos gerados por meio de levantamento bibliográfico no Plano Municipal de Saneamento de Resíduos Sólidos e no perfil socioeconômico de Cuiabá (IPDU).

Já o levantamento de campo foi realizado por meio de observações de campo nas margens do Córrego do Barbado com auxílio do checklist já descrito anteriormente (Quadro 2) realizando observações sobre existência de lançamentos de resíduos no córrego e em suas APPs, presença de animais e locais com bolsões de lixo.

\subsubsection{Habitação}

O levantamento dos dados de densidade populacional ou número de habitantes por área dos bairros da microbacia do Córrego do Barbado e os tipos de residências (próprias ou alugadas) foram obtidos no Perfil Socioeconômico de Cuiabá (IPDU). 
Quanto ao levantamento de campo foram observados, com auxílio do checklist em toda faixa de APP, a existência de ocupações ribeirinhas, os tipos de ocupação (residencial ou comercial, etc.) e por fim o acesso ao saneamento básico das ocupações.

\subsection{5 Água}

Para levantamento de dados referentes às características físicas da água do Córrego do Barbado, foram avaliados índices de ligações para abastecimento de água e esgoto, os tipos de abastecimento de água existentes e a descrição das ocorrências de inundação e alagamentos na bacia, por meio de levantamento na literatura em consultas em artigos científicos, perfil socioeconômico de Cuiabá (IPDU), Plano de Saneamento Básico de Cuiabá, reportagens de jornais eletrônicos, entre outras fontes.

A visita de campo consistiu em 2 etapas: observações de campo com auxílio de checklist (Quadro 2) e aplicação de questionários (Quadro 3).

Quadro 3-Questionário de diagnóstico ambiental do método VERAH-água

\begin{tabular}{|c|c|}
\hline \multicolumn{2}{|c|}{ Bairro: } \\
\hline $\begin{array}{l}\text { 1-Qual a dimensão da área impermeável do seu } \\
\text { terreno? } \\
\text { ( ) } 75 \text { a } 100 \% \\
\text { () } 50 \text { a } 75 \% \\
\text { ( ) } 25 \text { a } 50 \% \\
\text { ( ) } 0 \text { a } 25 \%\end{array}$ & $\begin{array}{l}\text { 4- Qual a disposição das águas pluviais? } \\
\text { ( ) Rede geral de esgoto } \\
\text { ( ) Rede coletora de águas pluviais } \\
\text { ( ) Armazenada em cisterna ou caixa d'água } \\
\text { ( ) Tubulação/rego do quintal para rua/calçada }\end{array}$ \\
\hline $\begin{array}{l}\text { 2- Qual a forma de disposição do esgoto doméstico? } \\
\text { ( ) Rede geral de esgoto } \\
\text { ( ) Rede coletora de águas pluviais } \\
\text { ( ) Fossa Sumidouro } \\
\text { ( ) Ligado diretamente ao córrego }\end{array}$ & $\begin{array}{l}\text { 5- Em épocas de chuva tem inundação do córrego? } \\
\text { ( ) Não transborda } \\
\text { ( ) Sim, existe transbordamento do córrego } \\
\text { 6- Existe caso de alagamento na residência? } \\
\text { ( ) Sim, água entra na residência } \\
\text { ( ) Não, água alaga somente a rua e calçada }\end{array}$ \\
\hline $\begin{array}{l}\text { 3-Qual o destino final do lixo de sua residência? } \\
\text { ( )Coletado pela prefeitura } \\
\text { ( )Enterrado no terreno ou em algum lugar próximo } \\
\text { ( )Queimado no terreno ou em algum lugar próximo }\end{array}$ & $\begin{array}{l}\text { 7- Qual motivo do alagamento? } \\
\text { ( ) Sistema de drenagem (boca de lobo) entupido } \\
\text { () Sistema de drenagem (boca de lobo) inexistente } \\
\text { ( ) Sistema de drenagem (boca de lobo) deficientes }\end{array}$ \\
\hline
\end{tabular}

Fonte: Autores (2017)

Nas observações de campo com auxílio do checklist foram analisados os fatores lançamento de esgoto in natura no córrego, presença de algas e mau odor na água.

A aplicação dos questionários teve a finalidade identificar e confirmar as áreas afetadas por alagamentos e inundações na bacia. Os questionários continham 7 perguntas do tipo fechada, onde os entrevistados poderiam marcar mais de uma alternativa (Quadro 3).

O público selecionado foram moradores dos bairros que fazem parte da bacia de contribuição do Viaduto da UFMT, delimitada em um estudo de Zorzo (2015) abrangendo os bairros: Jardim das Américas, Pico do Amor e Jardim Tropical (médio curso) onde há relatos de ocorrências de alagamentos e inundações.

Para a determinação do número de questionários a serem aplicados foram utilizadas as equações de Barbetta (2001), onde aproximadamente 1\% da população de cada bairro foi entrevistada, admitindo-se um erro máximo amostral de 5\% onde no total, 65 questionários foram aplicados. 
São Pedro, Aline; et al; Aplicação do Método VERAH no Diagnóstico Ambiental de uma Microbacia no Estado de Mato Grosso-Brasil. E\&S - Engineering and Science, (2018), 7:1.

\section{RESULTADOS E DISCUSSÕES}

\subsection{Diagnóstico Ambiental da microbacia do Córrego do Barbado}

\subsubsection{Vegetação}

De acordo com as medições realizadas por interpretação de imagem de satélite, a bacia possui apenas $1,41 \mathrm{Km}$ ou $1.412 \mathrm{~m}^{2}$ de área verde (Figura 8) e $0,27 \mathrm{Km}$ ou $272.1 \mathrm{~m}^{2}$ de áreas de preservação permanente (APP) com vegetação remanescente em torno de seu curso d' água.

Figura 8-Áreas verdes e delimitação das áreas de preservação permanente do córrego do barbado

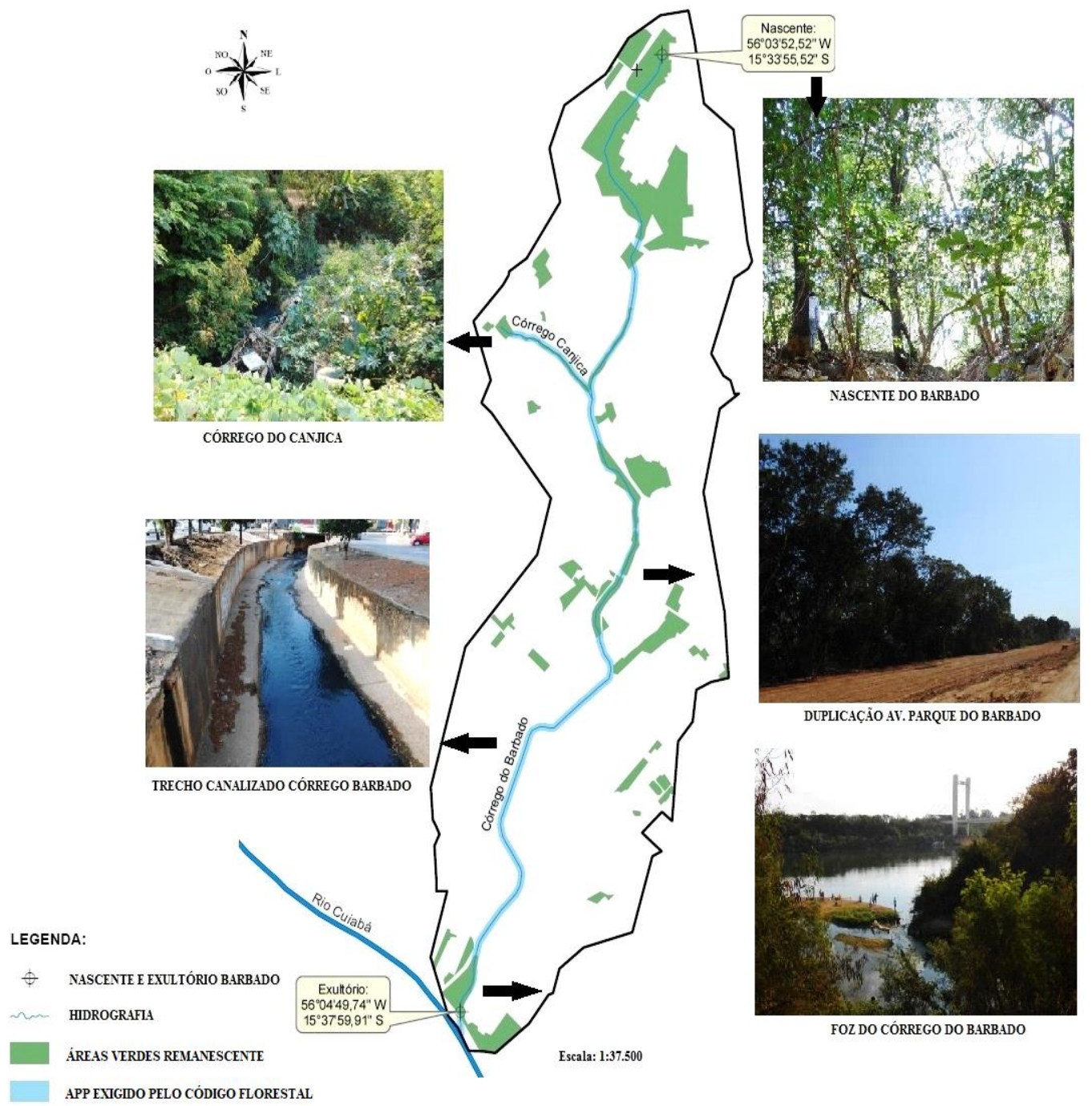

Fonte: Autores (2017)

De acordo com o Código Florestal No 12.651 de 2012 o Córrego do Barbado por estar inserido dentro da área urbana de Cuiabá deve conter faixas marginais de 30 metros em toda sua extensão, ou seja, $0,58 \mathrm{Km}$ ou $598.5 \mathrm{~m}^{2}$ de APP.

Nota-se que de $0,58 \mathrm{Km}$ ou $598.5 \mathrm{~m}^{2}$, a área de preservação encontra-se reduzida pela metade com $0,27 \mathrm{Km}$ ou $272.1 \mathrm{~m}^{2}$, isto se deve pelo intenso processo de urbanização, com ocupação desordenada dessas áreas por moradores ribeirinhos, impermeabilização das margens do córrego para execução de pavimentação asfáltica e obras de micro e macrodrenagem.

Apesar de ainda existir algumas áreas de preservação permanente nas margens do 
Córrego Barbado apenas as áreas que se encontram inseridas dentro do Parque Estadual Massairo Okamura, nascente e APP (alto curso) não estão descaracterizadas.

Em outros pontos ao longo da bacia a distribuição de vegetação diminui em direção à foz (médio e baixo curso).

O trecho do córrego da Av. Brasília até a Av. Arquimedes Pereira Lima, encontra-se em processo de desmatamento para a continuidade da obra de duplicação da Av. Parque do Barbado, obra esta prevista no Plano Diretor de Cuiabá.

É importante citar que a duplicação está sendo construída na margem direita da área de preservação do Córrego do Barbado, não respeitando o Código Florestal No 12.651 de 2012.

$\mathrm{Na}$ foz do córrego do Barbado a mata ciliar da sua margem direita encontra-se preservada, por estar localizada em uma área de difícil acesso, já a margem esquerda está descaracterizada por ocupação irregular, queimadas, lançamentos de resíduos e esgoto.

De acordo com os estudos realizados pelo projeto Radambrasil (BRASIL, 1982), a vegetação original da bacia do Córrego Barbado é a Savana Arbórea Aberta "campo cerrado", composta de árvores e arbustos tortuosos entremeados por tapete de gramíneo lenhoso associado a outras herbáceas, subarbustos e arbustos baixos das seguintes espécies: Qualea SP (pau-terra), Kielmeyerasp (pau-santo), Byrsonima (murici), Curatella americana (lixeira), Cayocar brasiliensis (pequi), Hancorniaspeciosa (mangaba), dentre outras.

Na década de 90, Bordest (2003), realizou um levantamento florístico da bacia o qual revelou que a região da nascente (alto curso), tem ocorrência predominante de vegetação do Cerrado, acompanhada de Capoeira, tendo como representantes: Ricinuscomunis (mamona) e crolon sp. (taquara-de-espinho). O estudo constatou ainda a existência de 55 famílias e 119 espécies nativas e 20 famílias e 23 espécies exóticas.

O cenário atual pouco se alterou no que se refere à distribuição e variabilidade da vegetação. Ainda se observa fito-fisionomias de Cerrado, Capoeira e Mata de galeria nas poucas manchas de vegetação que não foram tomadas pela ocupação urbana. O baixo curso do córrego do Babado, por sua vez, encontra-se com estreita faixa de vegetação ocupada principalmente por gramíneas e outras árvores (FARIA, 2013).

\subsubsection{Erosão e instabilidade das encostas}

No alto curso da bacia destaca-se a nascente do Córrego do Barbado localizada dentro do Parque Massairo Okamura, no bairro Morada do Ouro. Nesta área seu curso d'água encontra-se totalmente erodido e pode ser observado o assoreamento das suas encostas pela quantidade de pedras e terra dentro do curso d' água (Figura 9).

A nascente possui 20 metros de comprimento com profundidades variando entre 2 a 6 metros de altura e trechos variando entre 2 a 4 metros de largura.

No período de seca observou-se que, apesar da nascente estar localizada dentro de um parque de conservação, existe pouca vegetação rasteira contribuindo para o processo erosivo na área da nascente. 
Figura 9-Processos erosivos na microbacia do córrego do barbado baixo, médio e alto curso.

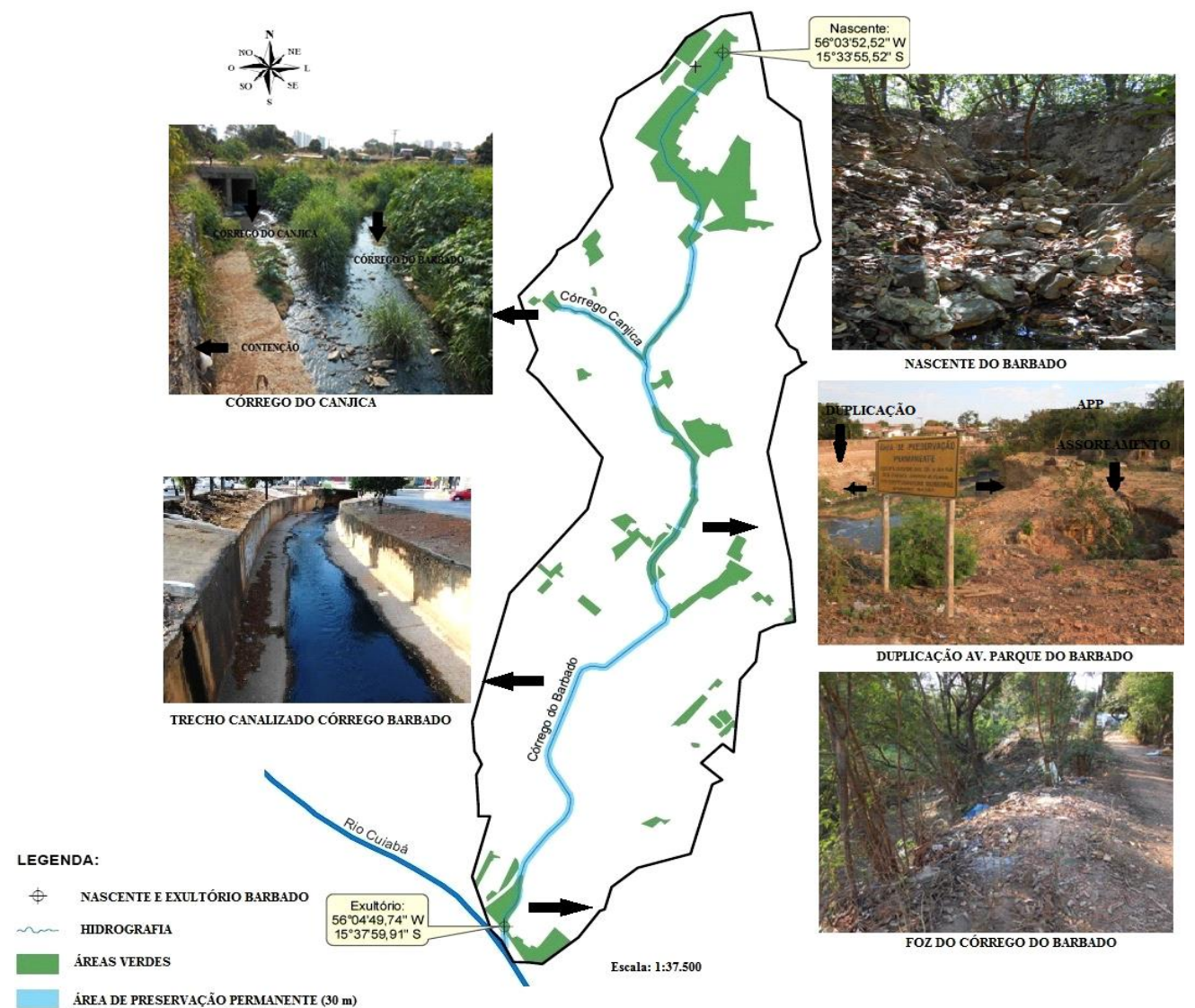

Fonte: Autores (2017)

Ainda no alto curso do córrego trecho localizado no bairro Canjica, ponto de encontro do Córrego do Barbado com o Córrego Canjica, seu afluente (localizado nas coordenadas geográficas $15^{\circ} 35^{\prime} 20.80^{\prime}$ 'S e $56^{\circ} 04^{\prime} 14.98^{\prime}$ 'O), há uma obra de contenção do talude na margem esquerda do córrego (Figuras 9), por uma estrutura chamada muro de Gabião, constituído por elementos metálicos (arames) costurados entre si, preenchidos com pedras.

No médio curso do córrego, avançados processos erosivos estão ocorrendo, desde o bairro Jardim das Américas no trecho da Av. Brasília até a Avenida Arquimedes Pereira Lima (coordenadas $15^{\circ} 36.09^{\prime} 35^{\prime} \mathrm{S}$ e $56^{\circ} 04^{\prime} 03.88^{\prime} \mathrm{O}$ ). Neste trecho encontra-se em andamento a duplicação da Av. Parque do Barbado (Figura 9).

Parte da área de preservação do córrego foi desmatada neste trecho, consequentemente iniciou-se o processo erosivo das encostas e o assoreamento do Córrego do Barbado (Figura 9). A erosão está com aproximadamente 5 metros de profundidade e todo este trecho do córrego está assoreado com acúmulo de sedimentos em seu curso.

Todo o trecho do baixo curso do córrego encontra-se canalizado, porém no bairro Praerinho (foz no rio), existe ocupação de população ribeirinha nas margens direita, a vegetação encontra-se em fase de descaracterização, há evidências de queimadas e erosão da encosta, que causa o assoreamento do leito do rio.

Em resumo, os processos erosivos das encostas e o assoreamento do leito foram mais acentuados nos trechos do alto curso, médio curso e foz do córrego, devido ao desmatamento de sua vegetação e construções inadequadas nas suas margens.

Esse fator encontra-se controlado no baixo curso devido à impermeabilização de sua superfície, onde as vias circundantes ao córrego estão pavimentadas, contribuindo para o controle da erosão na área da bacia. 
São Pedro, Aline; et al; Aplicação do Método VERAH no Diagnóstico Ambiental de uma Microbacia no Estado de Mato Grosso-Brasil. E\&S - Engineering and Science, (2018), 7:1

\subsubsection{Resíduos sólidos}

De acordo com estimativa de população para ano de 2012, realizada pelo Plano municipal de saneamento básico de Cuiabá (PMSB), a microbacia do Córrego do Barbado possui 66.166 habitantes e geração de resíduos per capita de $0,73 \mathrm{~kg} / \mathrm{hab}$.dia, produzindo um volume estimado de $1.450,8$ toneladas de resíduos por mês. A composição gravimétrica dos resíduos sólidos domiciliares da área urbana de Cuiabá segundo o PMSB (2013) é de 35,39\% de resíduo seco, $42,39 \%$ resíduo úmido e $22,22 \%$ de rejeitos.

Em avaliações de campo ao longo das margens do Córrego do Barbado observou-se o lançamento de resíduos sólidos dentro do curso d'água e em suas margens. Sendo os bairros: Bela Vista, Terra Nova e Praeirinho os que mais utilizam o córrego como destino final dos resíduos (Figuras 10.a até10. d).

Figura 10-Lançamento de resíduo no córrego (a), bolsões de lixo no bairro bela Vista (b), ocupação de app no bairro praeirinho (c) e lançamento de resíduos no bairro praeirinho (d)

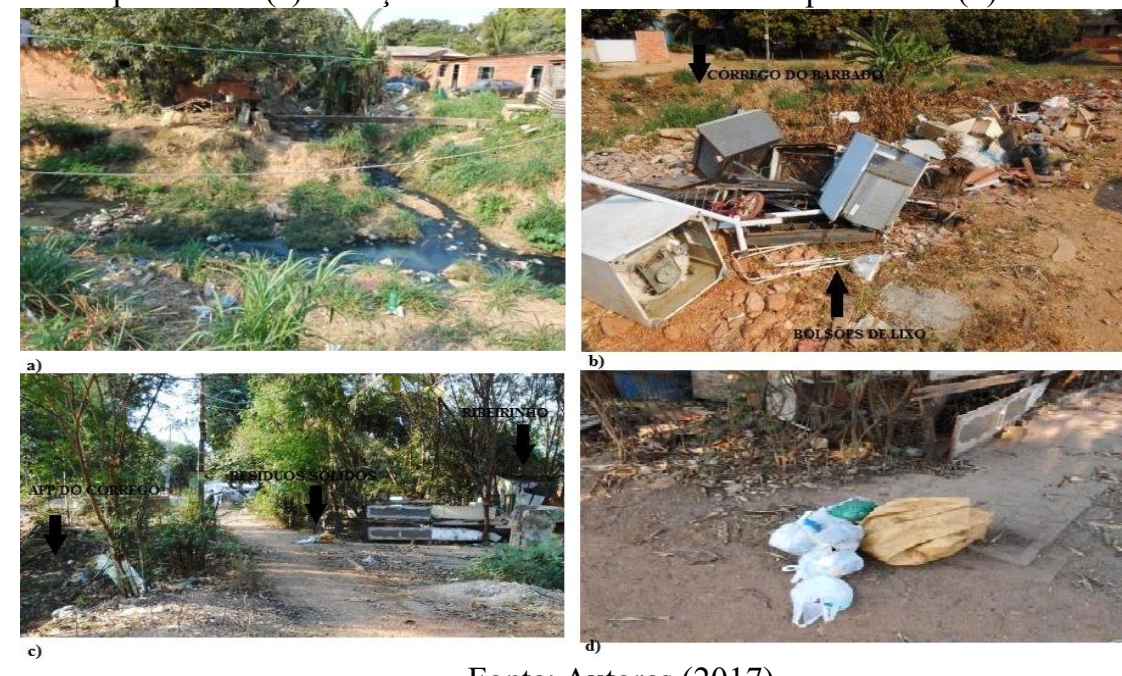

Fonte: Autores (2017)

Quanto à destinação final dos resíduos sólidos segundo Cuiabá (2010), 80\% são coletados pelo serviço municipal de limpeza, 13\% por caçamba de serviço de limpeza, 3\% são queimados e os outros $4 \%$ possuem outras formas de destinação final, sendo depositados em terrenos baldios ou logradouros, em rios, córregos ou lagos, entre outros.

Cuiabá, atualmente não conta com coleta seletiva de porta a porta, com isto os resíduos são encaminhados, misturados, diretamente para o aterro sanitário de Cuiabá que atualmente sofre com problemas de saturação de resíduos em sua área, dentre outros problemas (PMSB, 2013).

\subsection{4 Água}

O Córrego do Barbado percorre 8,95 Km de extensão, ainda não possui enquadramento aprovado, sendo assim ele é considerado Classe 2 pela Resolução CONAMA No430 de Maio de 2011.

Segundo Aquino (2011), a microbacia possui área de drenagem de 13,32 $\mathrm{Km}^{2}$, perímetro de 19,06 Km, coeficiente de compacidade (Kc) 1,83, fator forma (Kf) 0,12, desnível da nascente ao exutório $104 \mathrm{~m}$, densidade de drenagem $2,85 \mathrm{Km} / \mathrm{Km}^{2}$, sinuosidade 0,72 e comprimento principal do canal de 9,4 Km.

Quanto ao sistema de abastecimento de água, segundo Cuiabá (2010), a cobertura de abastecimento mostrou que cerca de $89 \%$ da população da microbacia utilizam a rede pública de abastecimento, $8 \%$ utilizam poço ou nascente e $3 \%$ utilizam outra forma de abastecimento. O sistema de tratamento da água é do tipo convencional e está sendo realizada por empresa 
privada de concessão de água e esgoto $\mathrm{CAB}$ ambiental.

Em visita de campo foram realizadas observações quanto à qualidade da água o Córrego do Barbado que apresenta avançado estado de degradação, lançamentos de esgoto domésticos, resíduos sólidos e assoreamento de suas margens.

Cuiabá (2010) relata quanto à disposição de esgoto, que $64 \%$ das habitações utilizam rede geral de esgoto ou a rede pluvial para destinação final de seus efluentes, $20 \%$ utiliza fossa séptica, $13 \%$ fossas rudimentares e $2 \%$ descartam diretamente nos rios ou vales, sendo os bairros Campo Verdes e Praeirinho os que mais recorrem a essa alternativa.

Com relação às ocorrências de alagamentos e inundações na microbacia do Barbado, o trecho do córrego localizado na Av. Fernando Corrêa da Costa, na região dos bairros Jardim das Américas e Pico do Amor (médio curso), há anos sofre com problemas relacionados às águas pluviais.

No ano de 2014 com a execução de obras de mobilidade urbana com intuito de melhorar a organização do espaço urbano para a realização da Copa do mundo, a qual Cuiabá foi sede, as ocorrências de alagamentos e inundações nesta Avenida se intensificaram em número e grau.

Duas obras foram executadas neste trecho da avenida, sendo elas o Viaduto Clovis Roberto de Queiroz (Viaduto da UFMT) e a duplicação da Avenida Parque do Barbado.

Falhas na execução da obra do viaduto da UFMT com a redução de $80 \mathrm{~m}$ de sua extensão e pela inexistência de projetos da rede de esgoto e drenagem, onde muitas bocas de lobos foram fechadas e entupidas, prejudicando o escoamento das águas pluviais nos períodos de chuva, contribuíram significantemente para aumento das ocorrências de alagamentos na região (GHISI, 2015).

A fim de identificar as áreas afetadas no trecho a Av. Fernando Correia e os fatores que agravam as ocorrências de alagamentos na região, os resultados dos questionários mostraram que $52 \%$ das residências da bacia de contribuição têm de 75 a $100 \%$ de seus lotes com áreas impermeáveis, ou seja, nesta região existe pouca área permeável para infiltração de água da chuva nas residências, aumentando assim a vazão de escoamento da chuva que é direcionada para as ruas e bocas de lobo.

Quanto à disposição de esgoto doméstico, segundo os dados levantados no relatório técnico de Marchetto et al. (2016), nos 3 bairros que fazem parte da bacia de contribuição do Viaduto da UFMT, existe rede coletora de esgoto e de águas pluviais, com isto $80 \%$ dos moradores afirmam que dispõem seus efluentes na rede de esgoto.

Quanto à disposição final dos resíduos sólidos na bacia de contribuição, $100 \%$ dos moradores afirmam que seus resíduos são coletados pelo serviço de limpeza pública municipal. Em relação à disposição das águas pluviais, $66 \%$ dos moradores afirmaram que em suas ruas existe rede coletora, já 34\% dos moradores afirmam que a água da chuva escoa para as ruas, calçadas e quintal, pois não tem boca de lobo próxima à sua residência.

Foi observado em campo que apesar de existir rede coletora de águas pluviais nestes bairros, muitas delas encontram-se obstruídas com sedimentos ou em mau estado de conservação ou em número insuficiente em uma quadra ou rua, o que contribui para o acumulo de água da chuva nas ruas adjacentes ao Córrego do Barbado.

Em períodos de chuva, 67\% dos moradores afirmaram que não ocorreram casos de inundação do Córrego do Barbado. Entretanto os outros 33\% dos moradores da bacia de contribuição afirmaram que houve casos de inundação do córrego, relatos estes dos moradores no bairro Jardim das Américas, ou seja, apesar da maioria dos moradores afirmarem não ter inundação em alguns bairros acontecem essas ocorrências.

Quanto às ocorrências de alagamentos, $74 \%$ dos moradores afirmaram que há ocorrências de alagamentos em seu bairro.

De acordo com relatos dos moradores as águas da chuva em sua maioria não entram em 
suas residências, atingindo apenas ruas e calçadas dificultando o trafego de pedestres e automóveis.

Quanto aos motivos que os moradores acreditam que ocasionam as ocorrências de alagamento neste trecho da bacia, $88 \%$ afirmaram que existe deficiência no sistema de drenagem (boca de lobo) em suas ruas e os outros $12 \%$ acreditam que seja pela inexistência de bocas de lobo e falta de limpeza e manutenção dos dispositivos de coleta.

Pode-se concluir com aplicação dos questionários que vários fatores influenciam as ocorrências de alagamentos e inundação neste trecho da bacia, como a total impermeabilização dos lotes das residências e ruas, ligações clandestinas de esgoto nas galerias de águas pluviais, deficiência, falta de limpeza e manutenção das bocas de lobo existentes.

\subsubsection{Habitação}

Na microbacia do Córrego do Barbado, os bairros que apresentam os maiores valores de densidade populacional, segundo dados do PMSB (2013), são os bairros, Bela Vista 152,34 hab/ha, seguido pelo bairro, Terra Nova com 117,38 hab/ha.

Para verificar o perfil das habitações da bacia, estas foram segregadas em habitações próprias ou já quitados, em aquisição, alugadas, cedidas e outras. Tendo em vista que $61,9 \%$ das moradias são próprias e já quitadas, $18,4 \%$ são alugadas e $6,6 \%$ são cedidas, pode-se concluir que investimentos estruturais podem ser feitos por parcela dessa população em seus domicílios para amenizar os efeitos de enchentes e alagamentos.

Conforme levantamento em campo, a microbacia apresenta predominância de área residencial sobre a comercial. Em praticamente todo o trecho do córrego do Barbado, há residências construídas ao longo de suas margens. Os dejetos gerados nestas residências, como dito anteriormente, são lançados diretamente no manancial superficial. Além disso, a vegetação nativa tem sido removida para locar as casas.

Partes das ocupações são realizadas por pessoas mais humildes, de poder aquisitivo mais baixo, porém observa-se que a ocupação irregular da APP não é realizada apenas por pessoas humildes, existe também ocupação por bairros de classe média alta, comércio, etc.

O quadro 8 apresenta uma síntese do diagnóstico ambiental da microbacia do Córrego do Barbado, bem como algumas recomendações para minimização e correção dos problemas encontrados.

Quadro 8- Síntese dos problemas e recomendações de ações para a bacia do córrego do barbado.

\begin{tabular}{|l|l|l|}
\hline \multirow{2}{*}{ TEMA } & \multicolumn{1}{|c|}{ PROBLEMAS DIAGNOSTICADOS } & \multicolumn{1}{c|}{ RECOMENDAÇÕES DE AÇÕES } \\
\hline \multirow{3}{*}{ Vegetação } & $\begin{array}{l}\text {-Existem apenas 1,4 Km de área verde na } \\
\text { bacia e menos de 0,5 Km de APP do córrego } \\
\text { preservada. }\end{array}$ & $\begin{array}{l}\text { - Recuperação e revitalização das áreas de } \\
\text { preservação permanente do córrego; } \\
\text {-Implementação de educação ambiental. }\end{array}$ \\
\hline \multirow{5}{*}{ Erosão } & $\begin{array}{l}\text { - Nascente antropizada; } \\
\text { - Processos erosivos acentuados (alto médio } \\
\text { e baixo curso). }\end{array}$ & $\begin{array}{l}\text {-Recuperação e revitalização da vegetação nas } \\
\text { margens dos córregos; } \\
\text {-Desocupação dos moradores das áreas de } \\
\text { risco de desmoronamento. }\end{array}$ \\
\hline \multirow{5}{*}{ Água } & $\begin{array}{l}\text { - } 80 \% \text { dos resíduos são coletados pelo } \\
\text { serviço de limpeza publica; } \\
\text {-Lançamento de lixo em toda extensão do } \\
\text { córrego do Barbado. }\end{array}$ & $\begin{array}{l}\text {-Universalizar em 100\% a coleta de resíduos } \\
\text { sólidos na bacia; } \\
\text { - Implementação de educação ambiental. }\end{array}$ \\
\hline $\begin{array}{l}\text {-89\% das residências são abastecidas pela } \\
\text { rede publica; } \\
\text { - Apenas 64\% das residências lançam seus } \\
\text { efluentes na rede coletora de esgoto; } \\
\text { - Lançamento de efluentes domésticos, e } \\
\text { lixo; }\end{array}$ & $\begin{array}{l}\text { - Universalizar em 100\% a coleta de esgoto, } \\
\text { abastecimento de água e sistema de drenagem } \\
\text { pluvial na bacia; } \\
\text {-Aumentar número e realizar manutenção nas } \\
\text { bocas de lobo na bacia de contribuição do } \\
\text { viaduto da UFMT; }\end{array}$ \\
\hline
\end{tabular}


São Pedro, Aline; et al; Aplicação do Método VERAH no Diagnóstico Ambiental de uma Microbacia no Estado de Mato Grosso-Brasil. E\&S - Engineering and Science, (2018), 7:1

\begin{tabular}{|l|l|l|}
\hline & $\begin{array}{l}\text { - Ocorrências alagamento e inundação no } \\
\text { trecho do córrego no viaduto da UFMT } \\
\text { (médio curso); } \\
\text {-Insuficiência e deficiências de dispositivos } \\
\text { de coleta de águas pluviais. }\end{array}$ & $\begin{array}{l}\text {-Implantar política de reuso de água pluvial na } \\
\text { microbacia; } \\
\text { - Implementação de educação ambiental. }\end{array}$ \\
\hline Habitação & $\begin{array}{l}\text {-Ocupação irregular das áreas de } \\
\text { preservação permanente do Córrego do } \\
\text { Barbado. }\end{array}$ & $\begin{array}{l}\text { - Desocupação das áreas de risco de } \\
\text { desmoronamento, deslizamento, alagamento e } \\
\text { inundação. }\end{array}$ \\
\hline
\end{tabular}

Fonte: Autores (2017)

\section{CONCLUSÃO}

De acordo com o levantamento e análise dos dados da microbacia dos 5 temas abordados pelo método VERAH todos apresentaram deficiências significativas que contribuem para as mudanças de comportamento hídrico da bacia, influenciando diretamente nas ocorrências de inundação e alagamentos no trecho do córrego do Barbado na Avenida Fernando Corrêa.

Os principais problemas encontrados no diagnóstico da bacia foram à existência de pouca área verde disponível, o alto índice de urbanização, lançamentos irregulares de esgoto e resíduos sólidos no curso d' água e ocupações irregulares das faixas de APP.

Faz-se necessário à adoção das ações recomendadas para os problemas encontrados, presente neste estudo assegurando assim a qualidade do curso d'água, visando garantir melhores condições de vida à população.

\section{AGRADECIMENTOS}

As autoras agradecem ao Programa de Recursos Hídricos da Faculdade de Arquitetura, Engenharia e Tecnologia da Universidade Federal de Mato Grosso, e Coordenação de Aperfeiçoamento de Pessoal de Nível superior - CAPES pela concessão de bolsa de estudos a um dos autores.

\section{REFERÊNCIAS BIBLIOGRÁFICAS}

AQUINO, A. M. Análise dos impactos ambientais decorrentes do processo intensivo de uso e ocupação do solo ocorrido na microbacia do Córrego do Barbado, Cuiabá-MT. Cuiabá - MT. 98 f. Dissertação (Mestrado) - Programa de Pós-Graduação em Recursos Hídricos, Universidade Federal de Mato Grosso, 2011.

BARBETTA, Pedro Alberto. Estatística Aplicada as Ciências Sociais. 4 ed. Florianópolis: Ed. da UFSC, 2001.

BORDEST, S. M. L. A bacia do Córrego do Barbado, Cuiabá- Mato Grosso. Cuiabá: Gráfica Print, 116p. 2003.

BRASIL. Ministério das Minas e Energia. Projeto RADAMBRASIL. Folha SD 21. Rio de Janeiro, 1982.

COLET, K. M. Avaliação do Impacto da Urbanização sobre o Escoamento Superficial na Bacia do Córrego do Barbado, Cuiabá-MT. Cuiabá, MT. Apresentado como dissertação de mestrado em Recursos Hídricos. Universidade Federal de Mato Grosso, 2012.

CUIABÁ. Prefeitura Municipal de Cuiabá- Evolução Urbana de Cuiabá. / IPDU - Instituto de Planejamento e Desenvolvimento Urbano. Cuiabá: 2010. 46 p. 
DELITTI, W.B.C. Ciclagem de nutrientes minerais em matas ciliares. Anais do Simpósio sobre Mata Ciliar, 1989. 88-98p.

FARIA, N. de. O. Estudo da impermeabilização, monitoramento, modelagem e simulação de cenários para a bacia do Barbado Cuiabá/MT. Dissertação de mestrado. Universidade Federal de São Carlos, 2013. 146 f.

GHISH, L. Secid assina convênio com UFMT para minimizar alagamentos em viaduto. Governo de Mato Grosso, Cuiabá, 23 Dez. 2015. Disponível em:<http://www.mt.gov.br//secid-assina-convenio-com-ufmt-para-minimizar-alagamentos-em-viaduto $>$. Acesso: 15 set. 2016.

MARCHETTO, M.; MAGALHÃE, S. L. M.; BAICERE, G. S.; ITO, J. B. B.; PESSOA, G. R. C.; RAIA, E. L.; NEVES, M. de. B.; CAMPOS, P. A. dos. S. Relatório do Levantamento dos Projetos Executados e a Serem e Executados na Região do viaduto da UFMT Avenida Fernando Corrêa da Costa. Universidade Federal de Mato Grosso. Cuiabá, MT, 2016.

OLIVEIRA, A. M.; ANDRADE, M. R. M.; SATO, S. E. ; QUEIROZ, W. Diagnóstico Ambiental de Microbacia Urbana: método VERAH. Guarulhos: Laboratório de Geoprocessamento, Universidade Guarulhos, 2008. 16p.

PMSB. Secretaria de serviços urbanos de Cuiabá. Plano Municipal de Saneamento básico de Cuiabá: Diagnóstico de Resíduos Sólidos. Cuiabá, MT, SMDU, 2013. p.181.

PONTUSCHKA, N. N.; PAGANELLI, T. I.; CACETE, N. H. Para ensinar e aprender Geografia. São Paulo: Cortez, 2007.

ROSIN, C., SILVA, I. L., BERTÃO, N. C., BRUM, B. R., LUZ, T. E. da. Diagnóstico Ambiental da Microbacia Urbana do Córrego Gambá, Cuiabá-MT. ENCICLOPÉDIA BIOSFERA, Centro Científico Conhecer - Goiânia, v.10, n.18; p. 2014.

SANTOS, A. B. F. Avaliação ambiental da Microbacia do Córrego Três Barras como subsídio para elaboração de um prognóstico na área de influência da Avenida Parque em Cuiabá - MT. Cuiabá - MT, 2013. 168p. Dissertação (Mestrado) - Programa de Pósgraduação em Engenharia de Edificações e Ambiental, Universidade Federal de Mato Grosso.

SOARES, C. de. F, MOURA, J. M. de, BILIO, R. de. S. Proposta de Recuperação de uma Área Degradada no Instituto Federal de Educação Ciência e Tecnologia de Mato Grosso - Cuiabá-MT. Instituto Brasileiro de Estudos Ambientais -IBEAS- III Congresso Brasileiro de Gestão Ambiental, 2012. Goiânia-GO.

SOUZA, M. B. de. Aplicação do método VERAH para subsidiar a elaboração de plano de gestão para a microbacia do Córrego Monjolo, Chapada dos Guimarães, MT. 2013. Dissertação de Mestrado em Recursos Hídricos. Universidade Federal de Mato GrossoUFMT, Cuiabá-MT, 2013.

TUCCI, C. E. M. Programa Nacional de Águas Pluviais. Ministério das Cidades PMSS, Brasília. 2007.

ZORZO, A. P. Estudo sobre os Condicionantes de Alagamentos na Avenida Fernando Corrêa da Costa, Cuiabá/MT. Cuiabá, 2015. Apresentado como trabalho de conclusão de curso. Universidade Federal de Mato Grosso, 2015. 